\title{
Bilateral osteochondritis dissecans of the elbow treated by Herbert screw fixation
}

\author{
Goro Inoue MD \\ Nagoya University Branch Hospital, Nagoya, Japan
}

\begin{abstract}
The case of a 15-year-old boy, a high-performance motocross rider, who developed bilateral osteochondritis dissecans of the elbow is described. Both lesions were successfully treated by Herbert screw internal fixation.
\end{abstract}

Keywords: Osteochondritis dissecans, elbow, motocross, Herbert screw

Osteochondritis dissecans of the elbow is an uncommon disorder and in one series it comprised only $6 \%$ of all patients with osteochondritis dissecans ${ }^{1}$. It most commonly affects the dominant arm of adolescent males who are engaged in throwing sports such as baseball. This lesion, however, has rarely been described in other athletic activities. The purpose of this paper is to report a high-performance motocross rider with bilateral lesions who was treated successfully using Herbert screw internal fixation.

\section{Case report}

A 15-year-old boy presented with a 6-month history of pain in both elbows during motorcycle activities. He trained for motocross for 3 years, spending 10-12 hours/week practising. There was no past history of significant direct trauma to his elbows. On clinical examination, he had tenderness over the radial head and capitellum with an effusion. The active range of movement of his elbow was $0^{\circ}$ of extension to $134^{\circ}$ of flexion in the right, and $-12^{\circ}$ of extension to $128^{\circ}$ of flexion in the left. Radiological examination showed rarefaction with a sclerotic rim of the capitellum bilaterally (Figure 1).

The right elbow was explored through a lateral approach. There was a defect in the articular surface with a loose fragment in situ. The fragment was almost entirely articular cartilage of full thickness, measuring $1 \times 2 \mathrm{~cm}$. The crater was curetted and

Address for correspondence: $G$. Inoue, Department of Orthopaedic Surgery, Nagoya University Branch Hospital, 1-1-20 Daikominami, Higashi-ku, Nagoya 461, Japan

(C) 1991 Butterworth-Heinemann Ltd. 0306-3674/91/030142-03 filled with iliac cancellous bone chips (Figure 2). The fixation with a Herbert screw was performed after adapting the fragment to its bed (Figure 3). The operative findings and procedure on the left elbow were similar to that on the right. After surgery the patient was placed in a posterior splint for 2 weeks, and then started on active exercises to develop his range of movement. Three months after surgery, he was allowed to return to motocross riding. Two years later he had a full range of movement in both elbows with no pain. His radiographs showed complete reossification of the capitellar cyst and normally contoured joint surfaces, with enlargement of the radial head bilaterally (Figure 4). He belonged to an organized competitive motocross club and was working out on the motocross 20-30 h weekly, aiming at becoming a professional rider.

\section{Discussion}

Although the cause of osteochondritis dissecans of the elbow is unknown and is controversial, several authors suggest that excessive use may bring on the disorder $^{1-3}$. Mitsunaga et al. reported that 38 of 57 patients in his series were participating in one or more sports activities at the onset of symptoms ${ }^{3}$, and that the sports most commonly involved were baseball (20), wrestling (14), and football (five); the other sports included tennis (three), basketball (two), golf (two), shotput (one) and gymnastics (one). To our knowledge, there was no case report of this lesion in motorcyclists. It was postulated that this injury had a strong relationship to compressive forces across the radiocapitellar joint from repetitive loading of the elbow.

In this case the arm often functioned as a shock absorber under stress during motocross riding. This exposed the patient's developing radiocapitellar joints to repetitive shear and compressive forces.

Various forms of treatment of osteochondritis dissecans have been used, including conservative treatment ${ }^{1,4}$, removal of loose body with or without drilling/curettage of the crater $^{2,4}$, simple excision of the fragment ${ }^{3}$, and fixation of the fragment with bone 

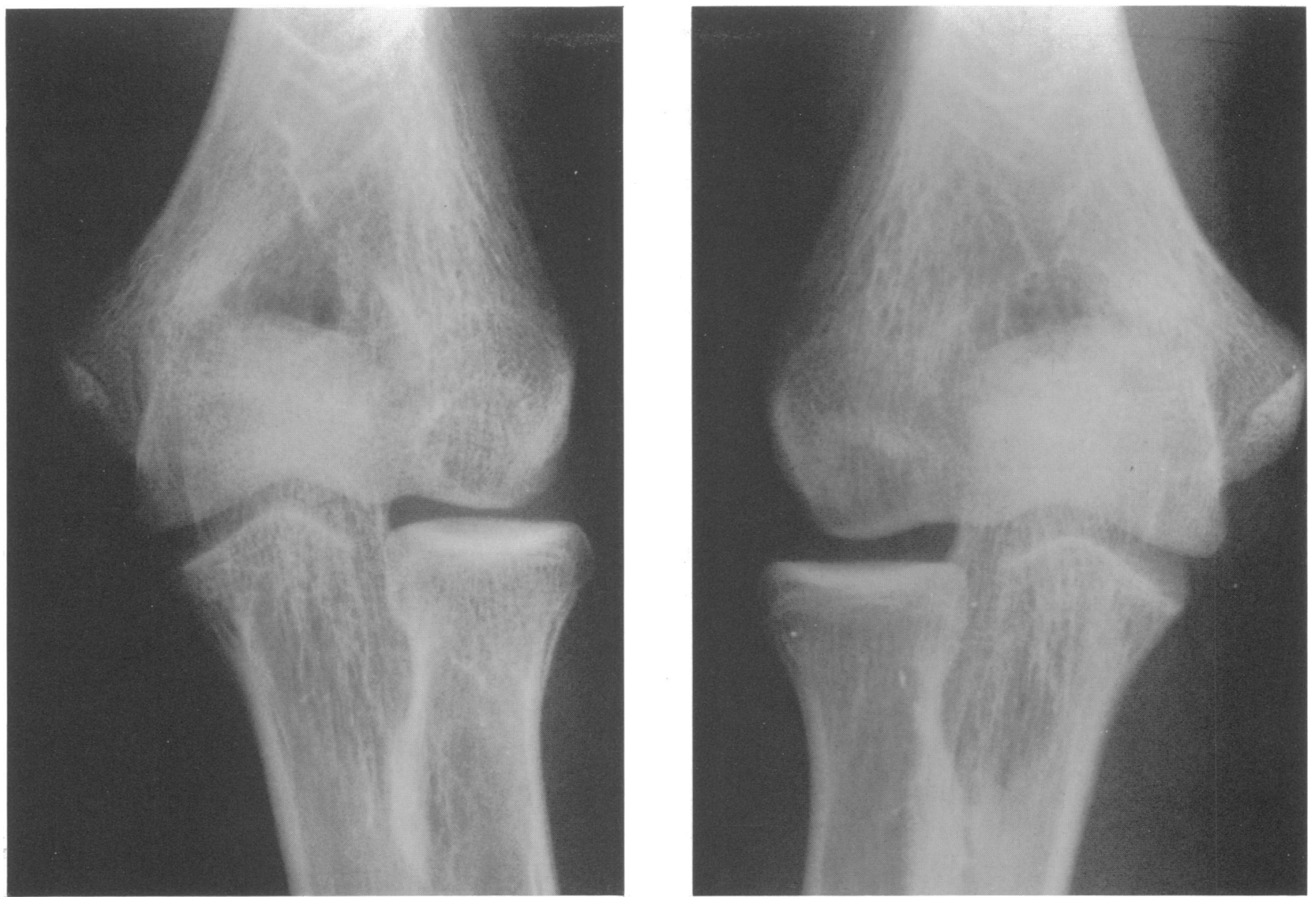

Figure 1. Preoperative radiographs of both elbows showing rarefaction surrounded by a zone of sclerosis of the capitellum

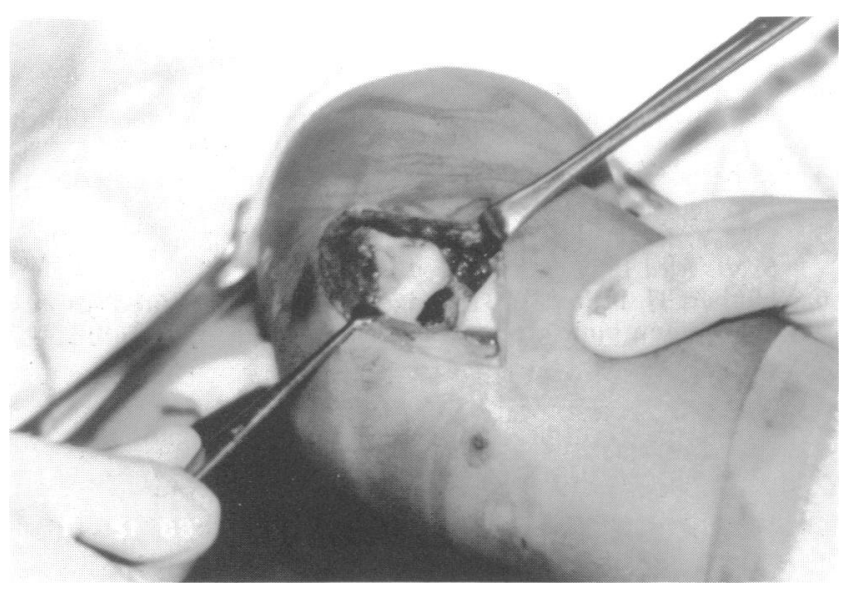

Figure 2. Intraoperative photograph showing the crater after removal of the fragment

pegging 5 . A review of the literature indicated that the opinion is generally against early operative intervention. However, Mitsunaga et al. reported that the outcome of the lesions still attached to the capitellum could not be predetermined, and they found that $42 \%$ progressed to become loose bodies ${ }^{3}$. If these fragments were securely fixed in place, it is possible that they might survive and help to reconstitute a

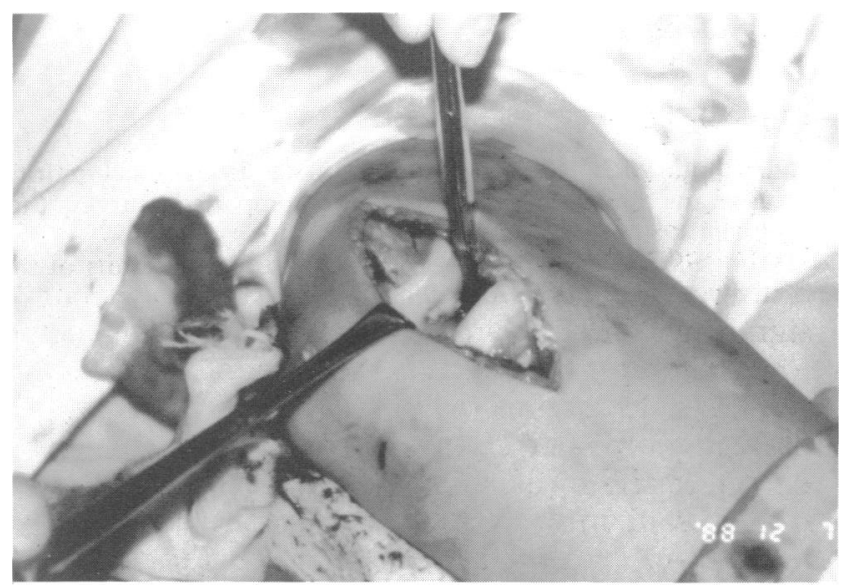

Figure 3. The fragment was fixed in situ using a Herbert screw

better articular surface for the capitellum.

The Herbert screw can be inserted through the articular cartilage without causing undue damage. It leaves no protruding head within the joint and provides a rigid fixation for small osteochondral fragments; this allows early movement of the elbow joint ${ }^{6}$. The result in this patient would suggest that further clinical trials are needed. 

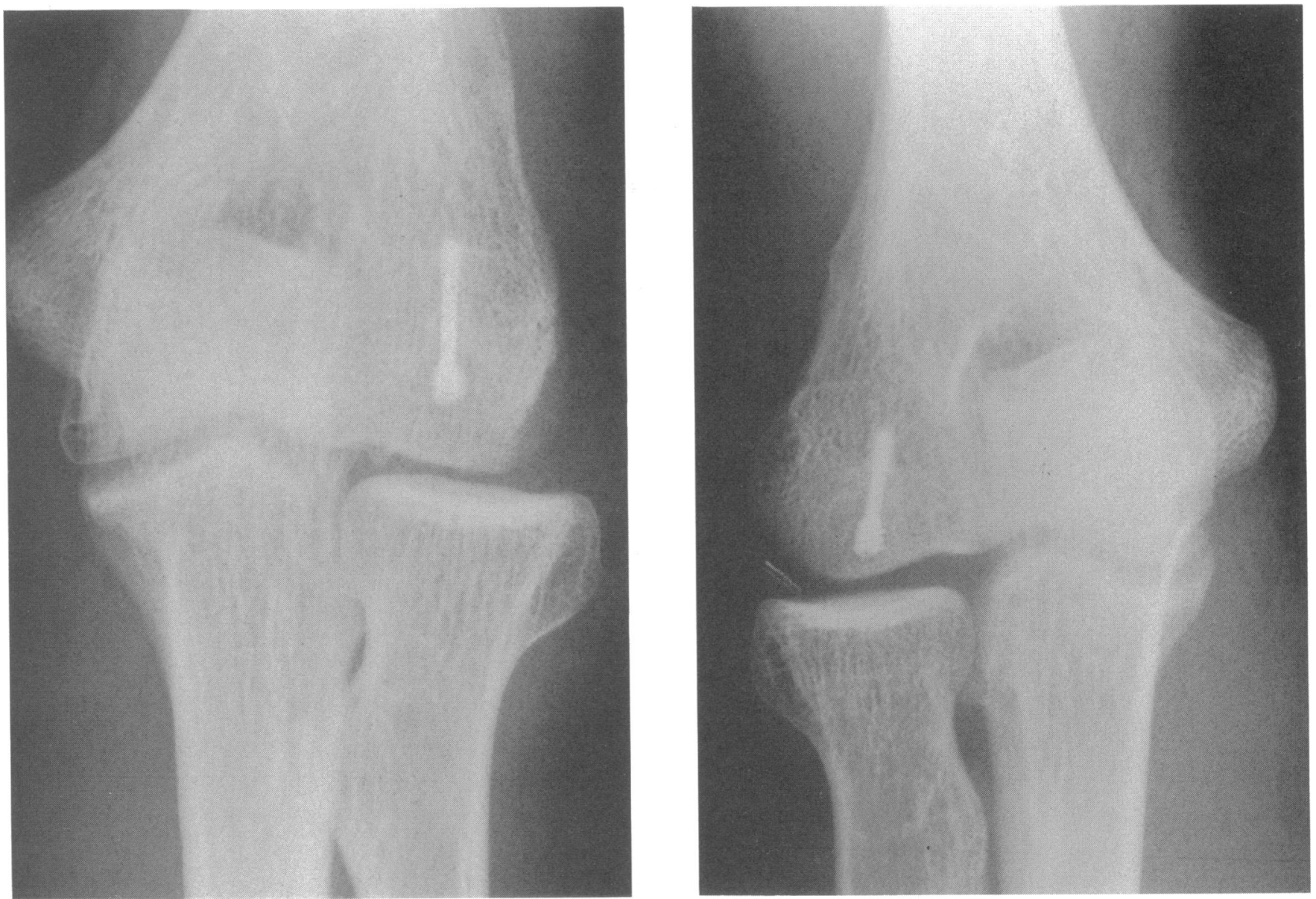

Figure 4. Radiographs 2 years after operation showing complete reossification of the capitellar cyst and normally contoured joint surfaces. The enlargement of both radial heads was recognized

\section{References}

1 Lindholm TS, Osterman K, Vankka E. Osteochondritis dissecans of elbow, ankle and hip: a comparison survey. Clin Orthop 1980; 148: 245-53

2 Woodward AH, Bianco AJ. Osteochondritis dissecans of the elbow. Clin Orthop 1975; 110: 35-41
3 Mitsunaga MM, Adishian DA, Bianco AJ. Osteochondritis dissecans of the capitellum. I Trauma 1982; 22: 53-5

4 Roberts N, Hughes R. Osteochondritis of the elbow joint. J Bone Joint Surg [Br] 1950; 32B: 348-60

5 Oka Y, Imai N. Treatment of little league elbow. Jpn J Orthop Sports Med 1987; 6: 223-36

6 Herbert TJ, Fisher WE. Management of the fractured scaphoid using a new bone screw. J Bone Joint Surg [Br] 1984; 66B: 114-23 